\title{
The role of micronutrients in the risk of urinary tract
}

\section{cancer}

Tomasz Golabek ${ }^{1}$, Jakub Bukowczan², Robert Sobczynski ${ }^{3}$, Jaroslaw Leszczyszyn ${ }^{4}$, Piotr L. Chlosta ${ }^{1}$

\author{
${ }^{1}$ Department of Urology, Jagiellonian University Medical College, Krakow, Poland \\ ${ }^{2}$ Department of Endocrinology and Diabetes, Royal Victoria Infirmary, Queen Victoria \\ Road, Newcastle upon Tyne, United Kingdom \\ ${ }^{3}$ Department of Cardiovascular Surgery and Transplantology, The John Paul II Hospital, \\ Krakow, Poland \\ ${ }^{4}$ EMC Health Care Clinic, Dublin, Ireland
}

Submitted: 9 May 2014

Accepted: 20 August 2014

Arch Med Sci 2016; 12, 2: 436-447

DOI: 10.5114/aoms.2016.59271

Copyright $\odot 2016$ Termedia \& Banach

\section{Abstract}

Prostate, bladder and kidney cancers remain the most common urological malignancies worldwide, and the prevention and treatment of these diseases pose a challenge to clinicians. In recent decades, many studies have been conducted to assess the association between supplementation with selected vitamins and elements and urinary tract tumour initiation and development. Here, we review the relationship between vitamins $A, B, D$, and $\mathrm{E}$, in addition to calcium, selenium, and zinc, and the risk of developing prostate, kidney and bladder cancer. A relatively consistent body of evidence suggests that large daily doses of calcium (> 2,000 mg/day) increase the risk of prostate cancer. Similarly, supplementation with $400 \mathrm{IU} /$ day of vitamin E carries a significant risk of prostate cancer. However, there have been many conflicting results regarding the effect of these nutrients on kidney and bladder neoplasms. Moreover, the role of other compounds in urinary tract carcinogenesis needs further clarification.

Key words: vitamins, elements, prostate cancer, kidney cancer, bladder cancer.

\section{Introduction}

Despite improvements in prostate cancer ( $\mathrm{PCa}$ ) treatment and decreased exposure to tobacco smoking and several occupational carcinogens that cause bladder (BC) and possibly kidney cancers (KC), urinary tract tumours still remain the common malignancies worldwide [1-6]. The risk of urological neoplasms appears to be influenced by a number of both modifiable and non-modifiable risk factors, including age, smoking, obesity, physical inactivity and diet [7-14]. Of these, diet in particular has been the focus of a considerable amount of research. This focus is in part due to the increasing awareness and utilization of complementary and alternative medicines, a movement that resulted from the belief that "natural" substances are innately safe and beneficial to one's health. In recent years, several studies have confirmed a significant increase in the consumption of vitamins, minerals and other micronutrients among both the general population and those who have been diagnosed with cancer or other chronic diseases [15-17]. Epidemiological observations

\author{
Corresponding author: \\ Tomasz Golabek MD, PhD \\ Department of Urology \\ Jagiellonian University \\ Medical College \\ 18 Grzegorzecka St \\ 31-531 Krakow, Poland \\ E-mail: elementare@op.pl
}


indicating that diets rich in fat and red or processed meats or diets low in fibre and vegetable intake are associated with a higher risk of various neoplasms, including gastrointestinal, breast, and prostate cancer, have further stimulated a global interest in nutrition-focused strategies and interventions for tumour chemoprevention.

Micronutrients are believed to act as pro- and anti-tumour risk modifiers throughout the entire complicated process of urogenital tumourigenesis. Although many studies have investigated the role of several vitamins and microelements in the aetiology and prevention of urinary tract tumours, disease progression, and associated complications, the results have often been conflicting or unclear. These conflicting results can be attributed to the complexity of the disease, but also to the lack of high quality, long term, randomised controlled studies that consider important confounding factors in the analyses.

We believe that there is a growing need for a combined review and critique of the vast amount of information that has recently been published, often with inconsistent, conflicting or non-evidence-based advice regarding the use of supplements as a means to prevent urinary tract cancers. This article aims to review the most up-todate information from laboratory, epidemiological and clinical studies to summarize which vitamins and other micronutrients have shown anti-prostate, -bladder, and -kidney cancer activity.

\section{Material and methods}

Our comprehensive search strategy searched the Medline/PubMed electronic database for articles published from the inception of the database until April 2014. We considered all human and animal research articles that were published in English and not classified as a case report, editorial, comment, letter, guideline, or news. The computer-based searches combined the following search terms related to vitamins $A, B, D, E$, multivitamins, calcium, selenium and zinc, as well as prostate, kidney and bladder cancer:

(i) Terms to identify vitamin A relevant exposures:

("Vitamin A" [Mesh] OR "vitamin a" [All Fields] OR "Retinoids" [All Fields] OR "retinoids" [All Fields] OR "Retinoic acid" [All Fields] OR "retinoic acid" [All Fields] OR "Carotenoids" [All Fields] OR "carotenoids" [All Fields] OR " $\beta$-Carotene" [All Fields] OR " $\beta$-carotene" [All Fields] OR "Beta-carotene" [All Fields] OR "beta-carotene" [All Fields] OR "Provitamin A" [All Fields] OR "provitamin A" OR "Xanthophylls" [All Fields] OR "xanthophylls" [All Fields [Mesh]).

(ii) Terms to identify vitamin B relevant exposures:

("Vitamin B" [Mesh] OR "vitamin B" [All Fields] OR "Vitamin B complex" [All Fields] OR "vitamin B complex" [All Fields] OR "Folic acid" [All Fields] OR "folic acid" [All Fields] OR "Folate" [All Fields] OR "folate" [Mesh]).

(iii) Terms to identify vitamin D relevant exposures:

("Vitamin D" [Mesh] OR "vitamin d" [All Fields] OR “25-hydroxyvitamin D"[All Fields]OR "25(OH)D” [All Fields] OR "Calcidiol" [All Fields] OR "calcidiol” [All Fields] OR "Ergocalciferol” [All Fields] OR "ergocalciferol" [All Fields] OR "Cholecalciferol" [All Fields] OR "cholecalciferol" [All Fields] OR "1 $\alpha, 25$-dihydroxyvitamin D3" [All Fields] OR "1,25-Dihydroxyvitamin D" [All Fields] OR "1,25-dihydroxyvitamin D" [Mesh]).

(iv) Terms to identify vitamin E relevant exposures:

("Vitamin E" [Mesh] OR "vitamin e" [All Fields] OR "Tocochromanols" [All Fields] OR "tocochromanols" [All Fields] OR "Tocotrienol" [All Fields] OR "tocotrienol" [All Fields] OR "Tocopherols" [All Fields] OR "tocopherols" [Mesh]).

(v) Terms to identify multivitamin and micronutrient relevant exposures:

("Vitamins " [Mesh] OR "vitamins" [All Fields] OR "Multivitamin" [All Fields] OR "multivitamin" [All Fields] OR "Multivitamins" [All Fields] OR "multivitamins" [All Fields] OR "Multivitamin-mineral" [All Fields] OR "multivitamin-mineral” [All Fields] OR "Multivitamin-multimineral" [All Fields] OR "multivitamin-multimineral" [All Fields] OR "Micronutrients" [All Fields] OR "micronutrients" [Mesh]). (vi) Terms to identify calcium relevant exposures:

("Calcium" [Mesh] OR "calcium" [All Fields] OR "CA" [All Fields] OR "Ca" [All Fields] OR "Calcium compounds" [All Fields] OR "calcium compounds" [Mesh]).

(vii) Terms to identify selenium relevant exposures:

("Selenium" [Mesh] OR "selenium" [All Fields] OR "SE" [All Fields] OR "Se" [All Fields] OR "Selenium compounds" [All Fields] OR "selenium compounds" [Mesh]).

(viii) Terms to identify zinc relevant exposures:

("Zinc" [Mesh] OR "zinc" [All Fields] OR "ZN" [All Fields] OR "Zn" [All Fields] OR "Zinc compounds" [All Fields] OR "zinc compounds" [Mesh]).

(ix) Terms to identify relevant outcomes:

("urinary tract cancer" [Mesh] OR "urinary tract cancers" [All Fields] OR "prostate cancer" [All Fields] OR "prostatic cancer" [All Fields] OR "prostatic neoplasm" [All Fields] OR "prostate neoplasm" [All Fields] OR "cancer of the prostate" [All Fields] OR "cancer of prostate" [All Fields] OR "kidney cancer" [All Fields] OR "kidney neoplasm" [All Fields] OR "cancer of the kidney" [All Fields] OR "cancer of kidney" [All Fields] OR "bladder cancer" [All Fields] OR "bladder neoplasm" [All Fields] OR "cancer of the bladder" [All Fields] OR "cancer of bladder" [Mesh]). 
Parts i-viii were combined with part ix using "AND" to search MEDLINE.

\section{Results}

The search strategy identified 32,327 articles about micronutrients and urinary tract tumours. After an initial screening based on titles and abstracts, a total of 218 papers remained for further evaluation.

\section{Discussion}

\section{Vitamin A}

Vitamin A is a generic term for a family of related compounds consisting of retinol and its derivatives, the retinoids [18]. Moreover, about 50 different carotenoids are viewed as pro-vitamin A compounds, meaning they can be converted to various forms of vitamin A, including retinol, retinal or retinoic acid [19]. Preformed vitamin A (retinol and retinyl esters) is found in cod liver oil, butter, eggs, animal products, and fortified grains, whereas provitamin A carotenoids are found in highly pigmented vegetables such as carrots, squash, and green leafy vegetables [18]. Vitamin A and its derivatives play many important roles in the human body but primarily are involved in both normal and cancerous cell differentiation [19]. Moreover, these molecules are required for appropriate organogenesis and are involved in the maintenance of epithelial tissues and immune function, in addition to mediating vision [18]. In addition, vitamin $\mathrm{A}$ has been shown to have several anticancer activities [19]. These activities are thought to rely on the antioxidant activities of vitamin A (carotenoids are involved in the scavenging of two types of reactive oxygen species), increases in the expression and function of a number of antioxidant and detoxifying enzymes (carotenoids and retinoids), and the proapoptotic effect of these molecules (carotenoids and retinoids) $[18,19]$.

Data from the most recent research suggest that the consumption of vitamin A and its analogues may lower the risk of developing kidney and bladder cancers. The supporting evidence is not, however, unambiguous [20]. Studer et al. used a prospective, randomized, multicenter trial to evaluate the effects of synthetic retinoid etretinate in 90 patients diagnosed with stage Ta and T1 superficial papillary bladder tumours who underwent transurethral resection of the tumour [21]. Although the time to first recurrence was similar in both arms of the study, the mean interval to subsequent $B C$ recurrence was significantly longer in patients taking vitamin $A$ analogues (20.3 months vs. 12.7 months, $p<0.006$ ). Similarly, the number of transurethral resections per patient per year was also significantly reduced in men and women taking the adjuvant etretinate. The authors concluded that retinoids could have a potential use in the primary but not secondary prevention of kidney and bladder cancers. Vitamin A plays a crucial role in maintaining normal physiology in the human body. In excess, however, this vitamin is highly toxic, causing fever, hypotension and respiratory failure. Because of these side effects and the absence of any positive results, the National Bladder Cancer Collaborative Group Study had to be terminated. This clinical trial aimed to prove that 13 -cis-retinoic acid could potentially be used as a chemoadjuvant treatment in patients at high risk of recurrent Ta and T1 bladder cancer [22]. The novel retinoids appear to be free of any serious side effects. These molecules could, therefore, be considered in bladder cancer prevention, provided that the daily recommended dosage is not exceeded.

There are no definitive data on the effect of vitamin A in prostate cancer pathogenesis. Neither observational nor epidemiological studies of the pure form of vitamin A could provide clear-cut answers [23]. However, the authors of the latest and also largest study investigating the role of vitamin A in prostate cancer aetiology prospectively analysed the serum retinol concentration of 22,000 men over the course of three years [24]. The results showed that the men with higher serum retinol concentrations prior to the study had a greater risk of cancer. The authors noted the same relationship between serum retinol concentration and the risk of developing a more aggressive form of cancer. Although the exact mechanisms underlying carcinogenesis under the observed conditions are not yet known, it is still possible that retinol may stimulate carcinogenesis in the prostate through sex hormones or cell membrane modifications.

\section{Calcium and vitamin D}

Calcium (Ca) is the most important nutrient in the diet because it is a structural component of bones, teeth, and soft tissues [25, 26]. Moreover, calcium is essential in many of the body's metabolic processes because it serves as a second messenger, transmitting signals between the plasma membrane and the intracellular machinery. The $\mathrm{Ca}^{2+}$ ion is involved in vital cellular processes including contraction, secretion, the induction and regulation of apoptosis, and the regulation of cell proliferation and differentiation [26]. In addition, extracellular calcium is a cofactor for clotting factors and adhesion molecules [25]. Dietary sources of calcium include dairy products, various leafy vegetables, and calcium-fortified foods $[25,26]$. The current recommended daily intake of calci- 
um is $1000 \mathrm{mg} /$ day for men aged 19 to 70 years and $1,500 \mathrm{mg} /$ day for men $>70$ years of age [27]. Calcium supplementation is not, however, free of risk. Some epidemiological data suggest that ingesting excess calcium from food and dietary supplements can increase the overall risk of prostate cancer. Similarly, the results of a meta-analysis that included 11 observational studies indicated that daily milk intake positively correlated with the risk of developing prostate cancer in the future [28]. A summary that pooled 37 prospective cohort studies and 4 interventional studies, all of which examined the effects of diet in prostate cancer and were published between 1966 and 2003, found a positive link between a high calcium intake (> 2,000 mg/day) and the increased risk of prostate cancer [29]. Gao et al. also confirmed these conclusions in their prospective study on men with high dairy and calcium intakes who were at increased risk of developing prostate cancer in the future [30].

The mechanisms underpinning these associations could be explained by the relationship between calcium and vitamin D. Too much calcium in the diet can subsequently reduce $1,25(\mathrm{OH})_{2}$ vitamin $D$ levels, which in turn enhances neoplastic cell de-differentiation and promotes the development of a more aggressive cancer. Moreover, this form of vitamin $D$ has previously been shown to harbour anti-proliferative and anti-metastatic properties [31]. The Health Professionals Follow-up Study confirmed the role of calcium-vitamin D balance in prostate cancer aetiology [32]. An analysis of the medical records of 47,750 men revealed that dietary and supplemental calcium intake is an independent risk factor for developing prostate cancer. Additionally, a daily calcium intake of more than $1,500 \mathrm{mg}$ a day is associated with more aggressive cancers (Gleason $>7$ ). It is worth mentioning that some authors could not confirm the carcinogenic effects of large amounts of dietary calcium in their studies. In those reports, however, daily calcium intake did not exceed $1,300 \mathrm{mg} /$ day [30, 33].

Vitamin $D$ refers to two fat-soluble substances, vitamin $D_{3}$ (cholecalciferol) and vitamin $D_{2}$ (ergocalciferol), and their metabolites, which are considered important nutrients for human health [34]. Vitamin D is primarily produced by sun-exposed skin. Vitamin $D$ is also absorbed by the gastrointestinal tract (mainly from dairy products, eggs and oily fish) to a much lesser degree, and vitamin $D$ deficiency is a common finding in many men. Vitamin D exerts a spectrum of biological effects. This vitamin is the precursor of the potent steroid hormone calcitriol, which regulates calcium and phosphate metabolism and is essential for bone mineralization [35]. Moreover, vitamin D has important homeostatic functions in fetal and adult development and in the differentiation of the endocrine, metabolic, neurological, epidermal, and immunological systems [34]. In addition, vitamin D plays a role in regulating the mechanisms controlling cell proliferation, differentiation, and growth, and may inhibit neoplastic cell cycle progression and tumour cell growth in addition to regulating the initiators of cellular angiogenesis in several cancer cell lines, including colonic cells from colorectal tumours, head and neck squamous cell carcinomas, and prostate and breast cancer cell lines [34]. Proper sun exposure may be protective against some types of neoplasms, such as digestive system cancers, and ovarian, breast, and cervical tumours [36]. However, the epidemiological results investigating the link between sun exposure and prostate cancer risk have been inconclusive thus far. A number of studies have reported an inverse correlation between sun exposure levels and both prostate cancer incidence [37-39] and mortality [40, 41]. On the other hand, ecological evidence from the U.S. has suggested that exposure to high levels of solar ultra-violet radiation is associated with an increased risk of PCa mortality [42]. Moreover, findings from the Prostate Testing for Cancer and Treatment (ProtecT) study demonstrated a reduced risk of both advanced cancer and high Gleason grade in men with PCa who spent less time outside over the course of their life, indicating low exposure to sunlight [43].

The link between dietary vitamin $\mathrm{D}$ and prostate cancer still remains inconclusive and unclear. A meta-analysis of six observational studies examining the relationship between vitamin D intake and prostate cancer risk found no such association [44]. However, the daily vitamin D intake of five out of six studies was below the recommended 400 IU per day for adults aged over 50 years (ranging from 132 to $376 \mathrm{lU} /$ day). Therefore, the true effects of dietary vitamin D on the prostate cancer risk could not have been determined by this study. Additionally, a recent meta-analysis by Gilbert et al. that scrutinized 25 prospective cohort/nested case-control or case-control studies examining the associations between vitamin D (dietary intake, circulating 25-hydroxy-vitamin-D $(25(\mathrm{OH}) \mathrm{D})$, and 1,25-dihydroxy-vitamin-D $\left.\left(1,25(\mathrm{OH})_{2} \mathrm{D}\right)\right)$ concentrations and prostate cancer found little evidence to support a major role of vitamin $D$ in preventing PCa incidence or progression [45]. There was no evidence of any association between dietary vitamin D intake and the risk of aggressive prostate cancer, and weak statistical evidence of a positive relationship with the total PCa risk was only observed if the meta-analysis was restricted to cohort/nested case-control studies only. Moreover, 
neither 25(OH)D nor $1,25(\mathrm{OH})_{2} \mathrm{D}$ was associated with total or aggressive prostate cancer risk or total PCa risk, respectively. The authors did observe some weak evidence of a small decrease in the risk of aggressive PCa with increasing 1,25-dihydroxy-vitamin-D levels. However, these findings were only based on two studies.

Interesting observations were generated by the ASCENT study, in which hormone-resistant prostate cancers were treated with a new form of oral vitamin D (DN-101) in addition to docetaxel chemotherapy [46]. Although the results showed no statistically significant decrease in prostate-specific antigen (PSA) in the vitamin D treatment group, the total survival rate in this group was significantly higher than the survival rate of the docetaxel only group. Moreover, DN-101 did not increase docetaxel-related toxicity. Vitamin D metabolism takes place primarily in the kidney, and one would expect an association between any kidney pathology, including cancer, and abnormal vitamin D levels. An inverse link between solar ultraviolet- $B$ radiation and the risk of renal cell carcinoma (RCC) was demonstrated in a global ecological study [47]. However, the prospective study, which examined $25(\mathrm{OH})$ vitamin D levels in $775 \mathrm{pa}-$ tients with RCC, produced conflicting results, showing no link between the two variables [48]. Moreover, two additional prospective and two case-control studies failed to show that vitamin $D$ could be linked with RCC pathogenesis [49-52]. The results should be interpreted with caution, however, as these studies had major design limitations, were generally underpowered, and did not include any information with regards to vitamin $D$ derived from sun-exposed skin. Studies exploring the link between genetically determined vitamin D receptor polymorphisms and RCC support the hypothesis that vitamin $\mathrm{D}$ may somehow be associated with RCC pathogenesis [53, 54]. Vitamin D also seems to be linked with urothelial carcinoma of the bladder (UCB), as vitamin D receptors are expressed in BC tissues [55]. Interesting results from Konety et al. indicated that vitamin $D$ has chemopreventive effects in bladder cancer [56]. In this study, the early installation of intravesical calcitriol in rats previously exposed to a carcinogen was associated with lower cancer burden and a less aggressive form of cancer. Thus far, only two studies have examined vitamin D status, as measured by serum 25-hydroxy-vitamin-D concentration, and risk of human bladder cancer [57, 58]. The Alpha-Tocopherol, Beta-Carotene Cancer Prevention (ATBC) Study, which was a randomised controlled trial conducted to determine the effects of $\alpha$-tocopherol and $\beta$-carotene supplements on cancer incidence in male smokers, found that lower serum 25(OH)D levels were associated with a nearly 2-fold increased risk of UCB compared to higher serum 25(OH)D levels [59]. In contrast, the Prostate, Lung, Colorectal, and Ovarian (PLCO) Cancer Screening Trial found no evidence of an association between vitamin $D$ level and risk of bladder cancer [58]. The difference between the results in these trials may be explained by the inclusion of women and non-smokers in the PLCO study.

\section{Selenium and vitamin $\mathrm{E}$}

Vitamin $\mathrm{E}$ is a collective term given to a group of four tocopherols and four tocotrienols [59]. The richest dietary sources of vitamin $E$ are nuts, seeds, vegetable oils, green leafy vegetables and fortified cereals [60]. All of the tocopherols and tocotrienols are potent antioxidants with lipoperoxyl radical-scavenging activities, while specific forms of vitamin $E$ have anti-inflammatory effects [59]. Because of these properties, $\gamma$ - and $\Delta$-tocopherols have been proposed as potentially useful chemopreventive agents. Experimental studies have shown that these molecules have an inhibitory effect on moderate colitis-promoted colon carcinogenesis and prostate cancer cell growth in athymic mice [59, 61]. Similarly, results from the ATBC suggested that vitamin E might carry chemopreventive properties [62]. This study showed a $32 \%$ decrease in the incidence of prostate cancer and a $41 \%$ decrease in prostate cancer-related mortality in men who received $50 \mathrm{mg}$ of $\alpha$-tocopherol daily for 5 to 8 years. Another study only reported a reduced incidence of advanced prostate cancer in the smoker subgroup [63].

Selenium (Se) is a trace element that occurs in both organic and inorganic forms. Selenium can be found in nuts, fish, chicken, beef, cereal, and eggs. Se contributes to human health by promoting proper enzyme function, proper redox function, and other effects on the immune response. This mineral also possesses antioxidant and cancer fighting properties, including the inhibition of cell proliferation, the induction of apoptosis and the modulation of immune function [64]. The anticancer effect of selenium was confirmed in both in vitro and in animal studies. In prostate cancer, this effect is mediated by the dose- and time-dependent inhibition of cancer cell growth and the induction of apoptosis in human PC3 prostate cancer cells [65]. In addition, selenium exhibits antiproliferative and antiangiogenic effects [66, 67]. Some epidemiologic data suggested that Se may have a protective role and may also reduce prostate cancer cell growth. The Nutritional Prevention of Cancer Trial (NPC) reported a 50\% lower incidence of prostate cancer in men who received $200 \mathrm{ng}$ of supplemental selenium daily [68]. The 
SELECT study, in turn, examined the effect of oral selenium $(200 \mu \mathrm{g} /$ day from L-selenomethionine) with or without vitamin E (400 IU/day of all-rac- $\alpha$-tocopheryl acetate) in 35,533 men over the course of 7 to 12 years [69]. The initial results were published after 5.5 years of follow-up and found no reduction in the risk of prostate cancer with either selenium or vitamin E supplements. However, after extending the follow-up period by another 2 years, the authors proved that vitamin $\mathrm{E}$ supplementation carried a statistically significant risk of prostate cancer [70]. Interestingly, the majority of the detected neoplasms had low-risk characteristics. The differences in the results of the SELECT and the Alpha-Tocopherol, Beta-Carotene Cancer Prevention Study may be attributed to the fact that all of the men in the ATBC study were long-term smokers, prostate cancer was not a primary end point, and the participants were not screened for PCa, with the result that the disease was detected at more advanced stages than in the SELECT study. In addition, the ATBC was designed and analysed as a factorial trial, so the reported effect of vitamin $E$ was estimated across the effect of $\beta$-carotene $[62,70]$.

In the SELECT study, the role of selenium supplementation in the prevention of primary prostate cancer could not be ascertained. Because the increased risk of PCa in the vitamin E and selenium combination group was not statistically significant, a potential protective effect of Se (in which Se decreases the increased risk associated with vitamin $\mathrm{E}$ alone) needs to be considered. On the other hand, no benefit was observed in men taking oral selenium only. Similarly, recent results from the Negative Biopsy Trial, a Phase 3, randomised, double-blind, placebo-controlled clinical trial, investigating the effect of selenised yeast supplementation on the incidence of prostate cancer in men at high risk for $\mathrm{PCa}$, found no effect of selenium supplementation during 5 years of follow-up [71].

With regards to the role of selenium in prostate cancer incidence, the differences in the findings from the NPC and the SELECT studies could well be explained by the insufficient Se levels in the NPC cohort as opposed to normal selenium levels in the SELECT study group [68-70].

It has been widely postulated that low body selenium stores increase the risk of cancer and that cancer itself can in turn cause low selenium levels. This hypothesis has been indirectly extrapolated from the study by Kwiatek et al. [72]. This group found greater Se concentrations in renal cancer compared to healthy kidney tissues. A recent study from Germany evaluated the link between selenium and renal cancer [73]. The study group consisted of 41 cancer patients and the control group contained 21 patients; the study measured the serum selenium and selenoprotein P (SePP) levels of both groups. SePP serves as the major Se transport protein in the blood and is a reliable biomarker of selenium status in marginally supplied individuals. The results of the study showed that a higher tumour grade and tumour stage at diagnosis correlated with lower SePP and Se concentrations. Moreover, a low Se status at diagnosis (SePP < $2.4 \mathrm{mg} / \mathrm{l}$ ) was associated with a worse 5 -year survival rate (20\%). These findings suggest that both Se and SePP concentrations have a prognostic and possibly preventive value in RCC. Further prospective studies are therefore highly valuable.

The role of selenium in bladder cancer aetiology is far from obvious. However, new evidence has recently emerged from epidemiological data. These data support a potential preventive role of selenium against bladder cancer [74]. The latest meta-analysis, which pooled 7 published studies encompassing a total of 1,910 cancer patients and 17,339 control patients, estimated that the total cancer incidence was greater in patients with low serum selenium concentrations. The protective effect of this trace element was only observed in women. This finding could possibly be attributed to sex-specific Se accumulation and excretion. However, a meta-analysis of studies examining selenium supplementation and the risk of primary bladder cancer, its incidence and mortality produced contrasting results [75]. This study revealed protective effects of Se that were only observed in men.

Vitamin $E$ has been noted to have a similar link with bladder cancer. The available supporting evidence is inconsistent and shows no clear association. The Danish Diet Cancer and Health Study supports a protective effect of dietary, but not supplemental, $\beta$-carotene on bladder cancer [76]. This study included 55,557 men and women aged 50-64 years at the commencement of the study who had no previous diagnosis of cancer. The data were collected through the completion of a detailed food frequency questionnaire that included information on the consumption of vitamins $C, E$, folate, and $\beta$-carotene from both the diet and supplements. For a median of 10.6 years of follow-up, no association between vitamin $\mathrm{E}$ and bladder cancer was found. However, the Cancer Prevention Study II, which analysed 991,522 adult Americans, found that 10 years of regular vitamin E supplementation resulted in lower bladder cancer-related mortality rates [77]. However, this chemoprotective effect was not seen when vitamin E was taken for less than 10 years. A further sub-analysis of the SELECT study, which evaluated 34,887 men taking selenium or vitamin $\mathrm{E}$ or se- 
lenium with vitamin E for 7.1 years, was recently published [78]. This analysis did not confirm the protective role of selenium or vitamin $\mathrm{E}$ in lowering bladder cancer risk.

Preclinical studies have shown that vitamin $\mathrm{E}$ reduces the risk of renal cancer in both men and women [79]. This finding was also supported by the lowa Women's Health Study [64] and an Italian case-control study [48]. Larger case-control studies could not, however, confirm previously observed results [80, 81]. Before vitamin E supplementation is recommended as a primary preventive measure against cancers, one should also consider the results of a meta-analysis by Miller et al. [82]. This study pooled data from 135,967 patients from 19 clinical studies, showing increased mortality rates in both men and women taking $\geq 400 \mathrm{IU} /$ day of vitamin E. Thus, based on the currently available evidence, the widespread use of tocopherol supplements in urologic cancer prevention cannot be safely recommended.

\section{B vitamins}

Vitamin B is a family of water soluble substances found in many foods, particularly citrus fruits, leafy green vegetables, cruciferous vegetables, cereals, and liver [83]. Several studies have postulated a link between the metabolism of specific forms of vitamin $B$ and carcinogenesis. Folate (naturally occurring vitamin B9), $\mathrm{B}_{12}$ and $\mathrm{B}_{6}$ are involved in a one-carbon metabolic pathway necessary for both cell proliferation and gene expression [84]. Historically, carcinogenesis was thought to primarily arise from de novo DNA mutations. Recently, however, epigenetic mechanisms that alter gene expression without affecting the DNA sequence have attracted increasing attention as playing an equal or even greater role in cancer development and progression. The role of B vitamin-mediated DNA methylation in carcinogenesis has been increasingly recognised as a novel target in cancer chemoprevention. The availability of methyl groups is largely dependent on serum folate levels, which provide methyl groups for homocysteine-methionine conversion in the form of 5 -methyltetrahydrofolate. This reaction is catalysed by a vitamin $B_{12}$-dependent enzyme. In effect, methionine becomes S-adenosyl methionine, a potent and universal methyl donor that participates in various biochemical processes, including DNA methylation [85]. Additionally, folate may play a protective role in cancer development by promoting the synthesis of thymidylate from uracil, lowering the chances of double-strand breaks due to the mis-incorporation of uracil and also ensuring the appropriate mismatch repair.

Global DNA hypomethylation with gene-specific hypermethylation is one of the most common epigenetic patterns observed in the development and progression of numerous tumours, including prostate cancer. In the prostate, the methylation-induced silencing of tumour suppressor genes appears to be the driving force in cancer development [86]. Interestingly, both a deficiency and excess of one-carbon nutrients have been hypothesised to increase prostate cancer risk [85, $87,88]$. This observation has been suggested by conflicting results from epidemiological research and may reflect a possible dual role of folate in prostate carcinogenesis $[85,89,90]$. Low folate levels were observed in murine prostate cancer models [91]. Conversely, folate deficiency stopped the progression of pre-existent prostate cancer in murine models, and high serum folate levels were associated with an increased progression rate in patients with existing prostate cancer $[87,92]$. Because several countries fortify foods with folate, a better understanding of the true effects of folate in prostate cancer development and progression is necessary to inform appropriate dietary recommendations [93]. The effect of folate on prostate carcinogenesis can be confounded by alcohol consumption and the C677T polymorphism of the methylenetetrahydrofolate reductase (MTHFR) gene. Heavy alcohol intake may carry a higher risk for prostate cancer [94]. Of the previous epidemiological studies which controlled for alcohol consumption, only four assessed the interaction between folate and alcohol intake, with inconsistent results $[90,95,96]$. A Swedish population-based study of 254 men diagnosed with prostate cancer found that higher plasma levels of vitamin $B_{12}$ and folate were associated with up to 3 -fold greater prostate cancer risk, suggesting that vitamin $B_{12}$ and folate may stimulate prostate cancer development [86]. A British population-based case-control study, systematic review and meta-analysis that measured the plasma concentrations of PSA, folate and vitamin $B_{12}$ in 1,461 men aged 50-69 years reported a significantly higher risk of prostate cancer in men with higher $B_{12}$ and folate plasma levels [87]. In contrast, a Canadian case-control study from 2012 that analysed plasma PSA and assessed dietary $B$ vitamin intake through the use of a questionnaire did not confirm the findings from the previous studies, instead finding that folate and vitamins $B_{2}, B_{6}$, and $B_{12}$ were not associated with prostate cancer risk. The study found that alcohol consumption was associated with increased prostate cancer risk, which was higher in men with low folate intake and even more so in those with the CC MTHFR genotype [97]. Similarly, a recent case-control study from the US compared plasma PSA levels with questionnaire-estimated dietary folate, $B_{6}$ and $B_{12}$ intake in 144 prostate cancer patients and found no association between 
$B$ vitamin intake (folate, $B_{12}$ and $B_{6}$ ) and prostate cancer risk. The study was, however, limited by its small sample size [98]. The most recent largescale, population-based case-control study from Norway analysed serum folate and $B_{12}$ concentrations in 3,000 prostate cancer patients, finding that high serum folate levels may be associated with a greater risk of prostate cancer [99]. However, the study did not find a positive correlation between serum $B_{12}$ levels and PCa risk.

\section{Zinc}

Zinc is an essential mineral that acts as a cofactor for more than seventy enzymes. A well-balanced diet provides, on average, $11 \mathrm{mg}$ of zinc per day. Zinc is primarily derived from meat, nuts, vegetables and zinc supplements. The hypothesis suggesting that zinc plays a protective role against prostate cancer was first described in studies showing that zinc levels were significantly lower in men with prostate cancer. Other trials also reported that zinc might halt cancer growth and invasion [64, 100]. However, the Health Professionals Follow-up Study reported a significantly higher rate of prostate cancer in men taking over $100 \mathrm{mg}$ of zinc daily for 10 years [101]. These men also had a greater risk of developing advanced and metastatic forms of the neoplasm. These results are supported by the latest Italian observational study, which also noted this harmful cause-andeffect relationship [102]. The question of whether consuming large amounts of zinc in one's diet (with or without the use of supplements) increases the risk of prostate cancer has yet to be answered.

The role of zinc in bladder cancer has not been well examined. Patients suffering from urothelial bladder carcinoma were found to have lower serum zinc levels [8]. Additionally, the authors of this study reported significantly lower levels of zinc in bladder cancer tissue as compared with healthy tissues. Hong et al. proved that a zinc-citrate compound has an anticancer effect (through the induction of apoptosis) in bladder cancer cells [103].

Zinc has also been investigated in patients with kidney cancer. A group of researchers from Belgium evaluated $\mathrm{Zn}$ and metallothionein (MT) levels in non-neoplastic and neoplastic kidney tissues from patients with urothelial carcinoma or adenocarcinoma [104]. The authors of this study found that zinc and metallothionein levels were lower in renal tumour tissues than healthy tissues from the same kidney. Kwiatek et al. confirmed these findings [72], noting significantly lower zinc concentrations in kidney cancer tissues than non-cancerous kidney tissues.

This observation may possibly reflect cancer activity. A study investigating a possible link between zinc and telomerase, an enzyme responsi- ble for the unlimited proliferation of cancer cells, found that zinc enhances telomerase activity in human renal cells, which may suggest an indirect role of zinc in promoting uncontrollable RCC cell proliferation [105].

\section{Multivitamins}

Multivitamins are the most frequently used over-the-counter dietary supplements [15]. Fifty percent of Americans regularly take dietary supplements, spending over $\$ 20$ billion annually for this purpose alone [16]. The motivation for the use of multivitamins varies, but is often fuelled by product health claims suggesting that these preparations will prevent chronic diseases and cancer [17]. The hypothesis that multivitamins may lower the chance of developing cancer has been derived from studies indicating that a diet rich in fruits and vegetables is associated with a lower risk of cardiovascular disease and cancer. Multivitamins contain the micronutrients classified as essential by the Institute of Medicine, which is why their use can be recommended to people with poor diets [106]. Of the numerous observational reports examining the association between supplement use and the risk of developing disease, only a few have specifically studied the use of multivitamins.

The data on the association between the use of multivitamins and prostate cancer risk are predominantly derived from a meta-analysis and two large randomised clinical trials [107-109]. These studies followed the publication of results from the large Case-Control Surveillance Study by Zhang et al. in 2009, which revealed that the long-term use of zinc-free multivitamins was not associated with an increased risk of prostate cancer in the 1,706 prostate cancer cases studied [110]. Subsequently, Stratton and Godwin conducted a systematic review and meta-analysis of all available data on this subject in 2011, assessing the effect of supplemental vitamins and minerals on prostate cancer risk, disease severity and cause-specific death [107]. None of the evidence suggested that the use of multivitamins affected the incidence or severity of prostate cancer. Although additional sensitivity analyses were conducted, no associations were found. Similarly, the Physicians' Health Study II, a large, randomised, double-blind, placebo-controlled trial of 14,641 male US physicians aged $\geq 50$ years, found no significant effect of multivitamin use on prostate cancer risk [108]. The most recent systematic review of double-blind, placebo-controlled, randomised clinical trials also does not support the hypothesis that dietary supplements are effective treatments for men suffering from prostate cancer [109].

The evidence suggesting that multivitamins reduce the risk of bladder cancer while increasing 
the risk of non-Hodgkin lymphoma is limited and is derived from case-control and cohort studies [111]. Conflicting observations arose from an analysis of 161,808 postmenopausal women from the Women's Health Initiative clinical trial, which found that $41.5 \%$ of all participants used multivitamins [15]. After medians of 8.0 and 7.9 years of follow-up in the clinical and observational cohorts, respectively, 9,619 neoplasms, including kidney and bladder cancers, were reported. However, multivariate-adjusted analyses found no correlation between multivitamin use and kidney and bladder cancer risk. The more recent VITamins And Lifestyle (VITAL) study from the US additionally confirmed that the long-term use of multivitamins did not reduce the risk of bladder cancer [112]. Three hundred and thirty incident urothelial cancers were found in the 77,050 eligible VITAL study participants after 6 years of follow-up. None of the studied multivitamins, mineral or anti-inflammatory supplements were significantly linked with bladder cancer risk in age-adjusted or multivariate analyses.

\section{Conclusions}

Patients with urological cancers, researchers and clinicians are faced with voluminous and often conflicting advice regarding nutritional supplementation. Any advice to the patients must be guided by the fact that there is no definite proof that any of the discussed micronutrients can impact the course of prostate, bladder or kidney neoplasms. Much of the data reviewed in this report were found in studies that showed significant diversity in presentation, methodology and technique. Moreover, other elements, such as absorption rates, transportation, metabolic pathways, and genetic and epigenetic factors could have further affected the reported outcomes. Although studies on micronutrients and urological cancer have been inconclusive, there is a relatively consistent body of evidence showing that large doses of calcium taken daily (> $2000 \mathrm{mg} /$ day) increase the risk of prostate cancer. Similarly, $400 \mathrm{IU} /$ day of vitamin E supplementation carries a significant risk of $\mathrm{PCa}$. However, there is no strong evidence for any beneficial or negative effect of vitamins $A$, $B, D$, selenium or zinc on prostate cancer. Similarly, the relationship between vitamins, zinc, selenium, and calcium and the incidence of renal and bladder malignancies remains unclear. Additional well-designed intervention studies investigating the potential association between micronutrients and prostate, kidney and bladder neoplasms and the underlying mechanisms of action are needed, especially considering that the incidence of urinary tract tumours is likely to continue increasing as a result of global population aging.

\section{Conflicts of interest}

The authors declare no conflicts of interest.

\section{References}

1. Ferlay J, Randi G, Bosetti C, et al. Declining mortality from bladder cancer in Europe. BJU Int 2008; 101: 11-9.

2. Levi F, Ferlay J, Galeone C, et al. The changing pattern of kidney cancer incidence and mortality in Europe. BJU Int 2008; 101: 949-58.

3. Bray F, Lortet-Tieulent J, Ferlay J, Forman D, Auvinen A. Prostate cancer incidence and mortality trends in 37 European countries: an overview. Eur J Cancer 2010; 46: 3040-52.

4. Bosetti C, Bertuccio P, Chatenoud L, Negri E, La Vecchia C, Levi F. Trends in mortality from urologic cancers in Europe, 1970-2008. Eur Urol 2011; 60: 1-15.

5. Zaborowska M, Szmit S, Szczylik C. Sorafenib in progressive castrate-resistant prostate cancer. Can we talk about a new therapeutic option? Arch Med Sci 2012; 8: 528-32.

6. Pikala M, Maniecka-Bryla I. Years of life lost due to malignant neoplasms characterized by the highest mortality rate. Arch Med Sci 2014; 10: 999-1006.

7. Golabek T, Darewicz B, Borawska M, Markiewicz R, Socha K, Kudelski J. Lead concentration in the bladder tissue and blood of patients with bladder cancer. Scand J Urol Nephrol 2009; 43: 467-70.

8. Golabek T, Darewicz B, Borawska M, Socha K, Markiewicz R, Kudelski J. Copper, zinc, and Cu/Zn ratio in transitional cell carcinoma of the bladder. Urol Int 2012; 89: 342-7.

9. Golabek T, Powroźnik J, Chłosta P, Dobruch J, Borówka A. The impact of nutrition in urogenital cancers. Arch Med Sci 2015; 11: 411-8.

10. Golabek T, Bukowczan J, Chłosta P, Powroźnik J, Dobruch J, Borówka A. Obesity and prostate cancer incidence and mortality: a systematic review of prospective cohort studies. Urol Int 2014; 92: 7-14.

11. Sandhu GS, Nepple KG, Tanagho YS, Andriole GL. Prostate cancer chemoprevention. Semin Oncol 2013; 40: 276-85.

12. Erdurak K, Dundar PE, Ozyurt BC, Negri E, La Vecchia C, Tay ZL. Smoking, occupation, history of selected diseases and bladder cancer risk in Manisa, Turkey. Eur J Cancer Prev 2014; 23: 58-61.

13. Piastowska-Ciesielska AW, Kozłowski M, Wagner W, Domińska K, Ochędalski T. Effect of an angiotensin II type 1 receptor blocker on caveolin-1 expression in prostate cancer cells. Arch Med Sci 2013; 9: 739-44.

14. Golabek T, Darewicz B, Kudelski J, et al. Cadmium in urothelial carcinoma of the bladder. Pol J Pathol 2014; 65: 55-9.

15. Neuhouser ML, Wassertheil-Smoller S, Thomson C, et al. Multivitamin use and risk of cancer and cardiovascular disease in the women's health initiative cohorts. Arch Intern Med 2009; 169: 294-304.

16. McGinnis JM, Birt DF, Brannon PR, et al. National Institutes of Health State-of-the-Science Conference Statement: multivitamin/mineral supplements and chronic disease prevention. Ann Intern Med 2006; 145: 364-71.

17. Neuhouser ML, Patterson RE, Levy L. Motivations for using vitamin and mineral supplements. J Am Diet Assoc 1999; 99: 851-4. 
18. Fritz $H$, Kennedy D, Fergusson D, et al. Vitamin A and retinoid derivatives for lung cancer: a systematic review and meta-analysis. PLoS One 2011; 6: e21107.

19. Donkena KV, Karnes RJ, Young CY. Vitamins and prostate cancer risk. Molecules 2010; 15: 1762-83.

20. Lee JE, Giovannucci E, Smith-Warner SA, Spiegelman D, Willett WC, Curhan GC. Intakes of fruits, vegetables, vitamins $A, C$, and $E$, and carotenoids and risk of renal cell cancer. Cancer Epidemiol Biomarkers Prev 2006; 15: 2445-52.

21. Studer UE, Jenzer S, Biedermann C, et al. Adjuvant treatment with a vitamin A analogue (etretinate) after transurethral resection of superficial bladder tumors. Final analysis of a prospective, randomized multicenter trial in Switzerland. Eur Urol 1995; 28: 284-90.

22. Prout GR Jr, Barton BA. 13-cis-retinoic acid in chemoprevention of superficial bladder cancer. The National Bladder Cancer Group. J Cell Biochem Suppl. 1992; 16: 148-52.

23. Schuurman AG, Goldbohm RA, Brants HAM, Van Den Brandt PA. A prospective cohort study on intake of retinol, vitamins $\mathrm{C}$ and $\mathrm{E}$, and carotenoids and prostate cancer risk (Netherlands). Cancer Causes Control 2002; 13: 573-82.

24. Mondul AM, Watters JL, Männistö S, et al. Serum retinol and risk of prostate cancer. Am J Epidemiol 2011; 173: 813-21

25. Power ML, Heaney RP, Kalkwarf HJ, et al. The role of calcium in health and disease. Am J Obstet Gynecol 1999; 181: 1560-9.

26. Bers DM. Calcium cycling and signaling in cardiac myocytes. Annu Rev Physiol 2008; 70: 23-49.

27. Ross AC, Taylor CL, Yaktine AL, Del Vall HB. Institute of Medicine. Dietary Reference Intakes for Calcium and Vitamin D. Washington, DC: The National Academies Press, 2011.

28. Qin LQ, Xu JY, Wang PY, Kaneko T, Hoshi K, Sato A. Milk consumption is a risk factor for prostate cancer: meta-analysis of case-control studies. Nutr Cancer 2004; 48: 22-7.

29. Dagnelie PC, Schuurman AG, Goldbohm RA, Van Den Brandt PA. Diet, anthropometric measures and prostate cancer risk: a review of prospective cohort and intervention studies. BJU Int 2004; 93: 1139-50.

30. Gao X, LaValley MP, Tucker KL. Prospective studies of dairy product and calcium intakes and prostate cancer risk: a meta-analysis. J Natl Cancer Inst 2005; 97: 1768-77.

31. Sonn GA, Aronson W, Litwin MS. Impact of diet on prostate cancer: a review. Prostate Cancer Prostatic Dis 2005; 8: 304-10.

32. Giovannucci E, Liu Y, Stampfer MJ, Willett WC. A prospective study of calcium intake and incident and fatal prostate cancer. Cancer Epidemiol Biomarkers Prev 2006; 15: 203-10.

33. Tavani A, Bertuccio P, Bosetti C, et al. Dietary intake of calcium, vitamin D, phosphorus and the risk of prostate cancer. Eur Urol 2005; 48: 27-33.

34. Moukayed M, Grant WB. Molecular link between vitamin D and cancer prevention. Nutrients 2013; 5: 39934021.

35. Feldman D, Krishnan AV, Swami S, Giovannucci E, Feldman $B$ J. The role of vitamin $D$ in reducing cancer risk and progression. Nat Rev Cancer 2014; 14: 342-57.

36. Wacker M, Holick MF. Sunlight and vitamin D: a global perspective for health. Dermatoendocrinol 2013; 5: 51-108.
37. Garland CF, Garland FC, Gorham ED, et al. The role of vitamin D in cancer prevention. Am J Public Health 2006; 96: 252-61.

38. Kricker A, Armstrong B. Does sunlight have a beneficial influence on certain cancers? Prog Biophys Mol Biol 2006; 92: 132-9.

39. van der Rhee HJ, de Vries E, Coebergh JW. Does sunlight prevent cancer? A systematic review. Eur J Cancer 2006; 42: 2222-32.

40. Hanchette CL, Schwartz GG. Geographic patterns of prostate cancer mortality. Evidence for a protective effect of ultraviolet radiation. Cancer 1992; 70: 2861-9.

41. Schwartz GG, Hanchette CL. UV, latitude, and spatial trends in prostate cancer mortality: all sunlight is not the same (United States). Cancer Causes Control 2006; 17: 1091-101.

42. Grant WB. Geographic variation of prostate cancer mortality rates in the United States: implications for prostate cancer risk related to vitamin D. Int J Cancer 2004; 111: 470-1.

43. Gilbert R, Metcalfe C, Oliver SE, et al. Life course sun exposure and risk of prostate cancer: population-based nested case-control study and meta-analysis. Int J Cancer 2009; 125: 414-23.

44. Huncharek M, Muscat J, Kupelnick B. Dairy products, dietary calcium and vitamin D intake as risk factors for prostate cancer: a meta-analysis of 26,769 cases from 45 observational studies. Nutr Cancer 2008; 60: 421-41.

45. Gilbert R, Martin RM, Beynon R, et al. Associations of circulating and dietary vitamin $\mathrm{D}$ with prostate cancer risk: a systematic review and dose-response meta-analysis. Cancer Causes Control 2011; 22: 319-40.

46. Beer TM, Ryan CW, Venner PM, et al. Intermittent chemotherapy in patients with metastatic androgen-independent prostate cancer: results from ASCENT, a double-blinded, randomized comparison of high-dose calcitriol plus docetaxel with placebo plus docetaxel. Cancer 2008; 112: 326-30.

47. Mohr SB, Gorham ED, Garland CF, Grant WB, Garland FC. Are low ultraviolet $B$ and high animal protein intake associated with risk of renal cancer? Int J Cancer 2006; 119: 2705-9.

48. Gallicchio L, Helzlsouer KJ, Chow WH, et al. Circulating 25-hydroxyvitamin $\mathrm{D}$ and the risk of rarer cancers: design and methods of the Cohort Consortium Vitamin D Pooling Project of Rarer Cancers. Am J Epidemiol 2010; 172: 10-20.

49. Mellemgaard A, McLaughlin JK, Overvad K, Olsen JH. Dietary risk factors for renal cell carcinoma in Denmark. Eur J Cancer 1996; 32A: 673-82.

50. Prineas RJ, Folsom AR, Zhang ZM, Sellers TA, Potter J. Nutrition and other risk factors for renal cell carcinoma in postmenopausal women. Epidemiology 1997; 8: 31-6.

51. Bosetti C, Scotti L, Maso LD, et al. Micronutrients and the risk of renal cell cancer: a case-control study from Italy. Int J Cancer 2007; 120: 892-6.

52. Wilson RT, Wang J, Chinchilli V, et al. Fish, vitamin D, and flavonoids in relation to renal cell cancer among smokers. Am J Epidemiol 2009; 170: 717-29.

53. Obara W, Suzuki Y, Kato K, Tanji S, Konda R, Fujioka T. Vitamin $D$ receptor gene polymorphisms are associated with increased risk and progression of renal cell carcinoma in a Japanese population. Int J Urol 2007; 14: 483-7. 
54. Karami S, Brennan P, Rosenberg PS, et al. Analysis of SNPs and haplotypes in vitamin D pathway genes and renal cancer risk. PLoS One 2009; 4: e7013.

55. Hermann GG, Andersen CB. Transitional cell carcinoma express vitamin D receptors. Scand J Urol Nephrol 1997; 31: 161-6.

56. Konety BR, Lavelle JP, Pirtskalaishvili G, et al. Effects of vitamin $D$ (calcitriol) on transitional cell carcinoma of the bladder in vitro and in vivo. J Urol 2001; 165: 253-8.

57. Mondul AM, Weinstein SJ, Männistö S, et al. Serum vitamin D and risk of bladder cancer. Cancer Res 2010; 70: 9218-23.

58. Mondul AM, Weinstein SJ, Horst RL, Purdue M, Albanes D. Serum vitamin D and risk of bladder cancer in the Prostate, Lung, Colorectal, and Ovarian (PLCO) Cancer Screening trial. Cancer Epidemiol Biomarkers Prev 2012; 21: 1222-5.

59. Jiang Q. Natural forms of vitamin E: metabolism, antioxidant, and anti-inflammatory activities and their role in disease prevention and therapy. Free Radic Biol Med 2014; 72C: 76-90.

60. Rizvi S, Raza ST, Ahmed F, Ahmad A, Abbas S, Mahdi F. The role of vitamin $E$ in human health and some diseases. Sultan Qaboos Univ Med J 2014; 14: e157-65.

61. Fleshner N, Fair WR, Huryk R, Heston WDW. Vitamin $E$ inhibits the high-fat diet promoted growth of established human prostate Incap tumors in nude mice. J Urol 1999; 161: 1651-4.

62. Heinonen OP, Albanes D, Virtamo J, et al. Prostate cancer and supplementation with alpha-tocopherol and beta-carotene: incidence and mortality in a controlled trial. J Natl Cancer Inst 1998; 90: 440-6.

63. Chan JM, Stampfer MJ, Ma J, Rimm EB, Willett WC, Giovannucci EL. Supplemental vitamin E intake and prostate cancer risk in a large cohort of men in the United States. Cancer Epidemiol Biomarkers Prev 1999; 8: 893-9.

64. Santillo VM, Lowe FC. Role of vitamins, minerals and supplements in the prevention and management of prostate cancer. Int Braz J Urol 2006; 32: 3-14.

65. Dong Y, Zhang H, Hawthorn L, Ganther HE, Ip C. Delineation of the molecular basis for selenium-induced growth arrest in human prostate cancer cells by oligonucleotide array. Cancer Res 2003; 63: 52-9.

66. Toś-Luty S, Obuchowska-Przebirowska D, Latuszyńska J, Musik I, Tokarska-Rodak M. Comparison of histological and ultrastructural changes in mice organs after supplementation with inorganic and organic selenium. Ann Agric Environ Med 2003; 10: 87-91.

67. Klein EA, Thompson IM. Chemoprevention of prostate cancer: an updated view. World J Urol 2012; 30: 189-94.

68. Clark LC, Combs GF Jr, Turnbull BW, et al. Effects of selenium supplementation for cancer prevention in patients with carcinoma of the skin. A randomized controlled trial. Nutritional Prevention of Cancer Study Group. JAMA 1996; 276: 1957-63.

69. Lippman SM, Klein EA, Goodman PJ, et al. Effect of selenium and vitamin $\mathrm{E}$ on risk of prostate cancer and other cancers: the selenium and vitamin E cancer prevention trial (SELECT). JAMA 2009; 301: 39-51.

70. Klein EA, Thompson IM Jr, Tangen CM, et al. Vitamin E and the risk of prostate cancer: the Selenium and $\mathrm{Vi}$ tamin E Cancer Prevention Trial (SELECT). JAMA 2011; 306: 1549-56.

71. Algotar AM, Stratton MS, Ahmann FR, et al. Phase 3 clinical trial investigating the effect of selenium sup- plementation in men at high-risk for prostate cancer. Prostate 2013; 73: 328-35.

72. Kwiatek WM, Drewniak T, Gajda M, Gałka M, Hanson AL, Cichocki T. Preliminary study on the distribution of selected elements in cancerous and non-cancerous kidney tissues. J Trace Elem Med Biol 2002; 16: 155-60.

73. Meyer HA, Endermann T, Stephan C, et al. Selenoprotein $\mathrm{P}$ status correlates to cancer-specific mortality in renal cancer patients. PLoS One 2012; 7: e46644.

74. Garland M, Morris JS, Stampfer MJ, et al. Prospective study of toenail selenium levels and cancer among women. J Natl Cancer Inst 1995; 87: 497-505.

75. Bardia A, Tleyjeh IM, Cerhan JR, et al. Efficacy of antioxidant supplementation in reducing primary cancer incidence and mortality: systematic review and meta-analysis. Mayo Clin Proc 2008; 83: 23-34.

76. Roswall N, Olsen A, Christensen J, Dragsted LO, Over$\operatorname{vad}$ K, Tjønneland A. Micronutrient intake and risk of urothelial carcinoma in a prospective Danish Cohort. Eur Urol 2009; 56: 764-70.

77. Jacobs EJ, Henion AK, Briggs PJ, et al. Vitamin C and vitamin E supplement use and bladder cancer mortality in a large cohort of US men and women. Am J Epidemiol 2002; 156: 1002-10.

78. Lotan Y, Goodman PJ, Youssef RF, et al. Evaluation of vitamin e and selenium supplementation for the prevention of bladder cancer in SWOG coordinated SELECT. J Urol 2012; 187: 2005-10.

79. Hu J, Mao Y, White K; Canadian Cancer Registries Epidemiology Research Group. Diet and vitamin or mineral supplements and risk of renal cell carcinoma in Canada. Cancer Causes Control 2003; 14: 705-14.

80. Nicodemus KK, Sweeney C, Folsom AR. Evaluation of dietary, medical and lifestyle risk factors for incident kidney cancer in postmenopausal women. Int J Cancer 2004; 108: 115-21.

81. Hu J, La Vecchia C, Negri E, DesMeules M, Mery L. Canadian Cancer Registries Epidemiology Research G. Dietary vitamin C, E, and carotenoid intake and risk of renal cell carcinoma. Cancer Causes Control 2009; 20: 1451-8.

82. Miller ER 3rd, Pastor-Barriuso R, Dalal D, Riemersma RA, Appel LJ, Guallar E. Meta-analysis high-dosage vitamin E supplementation may increase all-cause mortality. Ann Intern Med 2005; 142: 37-46.

83. Lin HL, An QZ, Wang QZ, Liu CX. Folate intake and pancreatic cancer risk: an overall and dose-response meta-analysis. Public Health 2013; 127: 607-13.

84. Ho E, Beaver LM, Williams DE, Dashwood RH. Dietary factors and epigenetic regulation for prostate cancer prevention. Adv Nutr 2011; 2: 497-510.

85. Hultdin J, Van Guelpen B, Bergh A, Hallmans G, Stattin P. Plasma folate, vitamin B12, and homocysteine and prostate cancer risk: a prospective study. Int J Cancer 2005; 113: 819-24.

86. Nelson WG, De Marzo AM, Isaacs WB. Prostate cancer. N Engl J Med 2003; 349: 366-81.

87. Collin SM, Metcalfe C, Refsum H, et al. Circulating folate, vitamin B12, homocysteine, vitamin B12 transport proteins, and risk of prostate cancer: a case-control study, systematic review, and meta-analysis. Cancer Epidemiol Biomarkers Prev 2010; 19: 1632-42.

88. Ulrich CM, Grady WM. Linking epidemiology to epigenomics - where are we today? Cancer Prev Res (Phila) 2010; 3: 1505-8. 
89. Vlajinac HD, Marinković JM, Ilić MD, Kocev NI. Diet and prostate cancer: a case-control study. Eur J Cancer 1997; 33: 101-7.

90. Weinstein SJ, Hartman TJ, Stolzenberg-Solomon R, et al. Null association between prostate cancer and serum folate, vitamin B6, vitamin B12, and homocysteine. Cancer Epidemiol Biomarkers Prev 2003; 12 1271-2.

91. Bistulfi G, VanDette E, Matsui SI, Smiraglia DJ. Mild folate deficiency induces genetic and epigenetic instability and phenotype changes in prostate cancer cells. BMC Biol 2010; 8: 6.

92. Tomaszewski JJ, Cummings JL, Parwani AV, et al. Increased cancer cell proliferation in prostate cancer patients with high levels of serum folate. Prostate 2011; 71: 1287-93.

93. Lucock M, Yates Z. Folic acid fortification: a double-edged sword. Curr Opin Clin Nutr Metab Care 2009; 12: 555-64.

94. Fillmore KM, Chikritzhs T, Stockwell T, Bostrom A, Pascal R. Alcohol use and prostate cancer: a meta-analysis. Mol Nutr Food Res 2009; 53: 240-55.

95. Pelucchi C, Galeone C, Talamini R, et al. Dietary folate and risk of prostate cancer in Italy. Cancer Epidemiol Biomarkers Prev 2005; 14: 944-8.

96. Stevens VL, Rodriguez C, Pavluck AL, McCullough ML Thun MJ, Calle E. Folate nutrition and prostate cancer incidence in a large cohort of US men. Am J Epidemiol 2006; 163: 989-96.

97. Kobayashi LC, Limburg H, Miao Q, et al. Folate intake, alcohol consumption, and the methylenetetrahydrofolate reductase (MTHFR) C677T gene polymorphism: influence on prostate cancer risk and interactions. Front Oncol 2012; 2: 100.

98. Vidal AC, Grant DJ, Williams CD, et al. Associations between intake of folate, methionine, and vitamins B12, B6 and prostate cancer risk in American veterans. J Cancer Epidemiol 2012; 2012: 957467.

99. de Vogel S, Meyer K, Fredriksen Å, et al. Serum folate and vitamin B12 concentrations in relation to prostate cancer risk-a norwegian population-based nested case-control study of 3000 cases and 3000 controls within the JANUS cohort. Int J Epidemiol 2013; 42: 201-10.

100. Platz EA, Helzlsouer KJ. Selenium, zinc, and prostate cancer. Epidemiol Rev 2001; 23: 93-101.

101. Leitzmann MF, Stampfer MJ, Wu K, Colditz GA, Willett WC, Giovannucci EL. Zinc supplement use and risk of prostate cancer. J Natl Cancer Inst 2003; 95: 1004-7.

102. Gallus S, Foschi R, Negri E, et al. Dietary zinc and prostate cancer risk: a case-control study from Italy. Eur Urol 2007; 52: 1052-6.

103. Hong SH, Choi YS, Cho HJ, Lee JY, Hwang TK, Kim SW. Induction of apoptosis of bladder cancer cells by zinc-citrate compound. Korean J Urol 2012; 53: 800-6.

104. Hellemans G, Soumillion A, Proost P, et al. Metallothioneins in human kidneys and associated tumors. Nephron 1999; 83: 331-40.

105. Nemoto K, Kondo Y, Himeno S, et al. Modulation of telomerase activity by zinc in human prostatic and renal cancer cells. Biochem Pharmacol 2000; 59: 401-5.

106. Panel on Dietary Antioxidants and Related Compounds, Subcommittee on Upper Reference Levels of Nutrients, Subcommittee on Interpretation and Uses of DRIs, Standing Committee on the Scientific Evaluation of Dietary Reference Intakes, Food and Nutrition
Board; Institute of Medicine. Dietary Reference Intakes for Vitamin C, Vitamin E, Selenium and Carotenoids. Medicine Io. Washington, DC: The National Academy Press, 2000.

107. Stratton J, Godwin M. The effect of supplemental vitamins and minerals on the development of prostate cancer: a systematic review and meta-analysis. Fam Pract 2011; 28: 243-52.

108. Gaziano JM, Sesso HD, Christen WG, et al. Multivitamins in the prevention of cancer in men: the physicians' health study II randomized controlled trial. JAMA 2012; 308: 1871-80.

109. Posadzki P, Lee MS, Onakpoya I, Lee HW, Ko BS, Ernst E. Dietary supplements and prostate cancer: a systematic review of double-blind, placebo-controlled randomised clinical trials. Maturitas 2013; 75 : $125-30$.

110. Zhang Y, Coogan P, Palmer JR, Strom BL, Rosenberg L. Vitamin and mineral use and risk of prostate cancer: the case-control surveillance study. Cancer Causes Control 2009; 20: 691-8.

111. Zhang SM, Calle EE, Petrelli JM, Jacobs EJ, Thun MJ. Vitamin supplement use and fatal non-Hodgkin's lymphoma among US men and women. Am J Epidemiol 2001; 153: 1064-70.

112. Hotaling JM, Wright JL, Pocobelli G, Bhatti P, Porter MP, White El. Long-term use of supplemental vitamins and minerals does not reduce the risk of urothelial cell carcinoma of the bladder in the VITamins And Lifestyle study. J Urol 2011; 185: 1210-5. 